Disponível em

ANRAD http://www.anpad.org.br/rac

RAC, Curitiba, v. 15, n. 2, art. 4, pp. 228-248, Mar./Abr. 2011

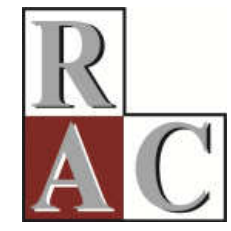

\title{
Estrutura de Maturidade das Dívidas das Empresas Brasileiras: um Estudo Empírico
}

\author{
Maturity Structure of Brazilian Company Debt: an Empirical Study
}

Wilson Toshiro Nakamura *

E-mail: wtnakamura@uol.com.br Universidade Presbiteriana Mackenzie São Paulo, SP, Brasil.

Michele Nascimento Jucá

E-mail: michele.juca@uol.com.br Universidade Presbiteriana Mackenzie São Paulo, SP, Brasil.

Douglas Dias Bastos E-mail: dobastos@uol.com.br Universidade Presbiteriana Mackenzie

São Paulo, SP, Brasil.

* Endereço: Wilson Toshiro Nakamura

Rua Correia de Lemos, 390, apto. 62, Chácara Inglesa, São Paulo/SP, 04140-000.

Copyright (C) 2011 RAC. Todos os direitos, até mesmo de tradução, são reservados. É permitido citar parte de artigos sem autorização prévia, desde que seja identificada a fonte. 


\title{
Resumo
}

O objetivo principal deste trabalho consiste em analisar os principais determinantes da estrutura de maturidade das dívidas, à luz das teorias baseadas nas imperfeições do mercado, bem como compreender o perfil do endividamento das empresas brasileiras de grande porte, detentoras de dívidas bancárias e emissoras de debêntures. A amostra consiste em 38 empresas brasileiras de grande porte emissoras de dívidas, analisadas no período entre 2002 e 2007, sendo utilizadas as técnicas econométricas de regressão cross-section e dados em painel, a fim de testar as hipóteses sobre a estrutura de maturidade das dívidas das empresas brasileiras. As variáveis Oportunidades de crescimento (OPOCR), Receita operacional líquida (LNROL), Alavancagem (ALAV), Maturidade dos ativos (MATA) e Rating Alto (RATA) apresentaram resultados estatisticamente significantes. Todavia, o sinal apresentado foi o contrário, divergindo do proposto pela teoria. Foi observado que, analisando à luz do referencial teórico levantado, apenas a variável Alíquota efetiva de tributos (TAXE) influencia o comportamento da maturidade das dívidas.

Palavras-chave: endividamento; maturidade das dívidas; imperfeições do mercado; dados em painel.

\begin{abstract}
The main objective of this study is to analyze the main factors for the maturity structure of debt based on theories relating to market imperfections, and also to understand the debt profile of large Brazilian companies, owners of bank debt and issuers of debentures. The sample consists of 38 large Brazilian companies, issuers of debt, analyzed between 2002 and 2007, using econometric cross-section techniques and panel data to test the hypotheses concerning the maturity structure of Brazilian company debt. The Growth opportunity (OPOCR), Net operating revenue (LNROL), Leverage (ALAV), Asset maturity (MATA) and High Rating (RATA) variables provided statistically significant results. However, the opposite sign was presented, diverging from the theory's hypotheses. Analyzing this based on the theoretical reference raised, it was observed that only the Effective tax rate (TAXE) variable influences debt maturity behavior.
\end{abstract}

Key words: indebtedness; debt maturity; market imperfections; panel data. 


\section{Introdução}

Existe uma literatura teórica e empírica extensa em finanças corporativas sobre a influência da combinação entre dívidas e patrimônio líquido, para minimizar o custo de capital ou maximizar o valor da empresa. Todavia, para que as empresas possam atingir sua estrutura ótima de capital, elas necessitam escolher não apenas a razão ideal entre dívidas e patrimônio líquido, mas também a maturidade adequada de suas dívidas. Significa dizer que, para obter uma estrutura ótima de capital, é necessário saber quanto e quando o fluxo de caixa futuro da empresa irá remunerar seus detentores de títulos.

Uma solução lógica seria a combinação entre a maturidade das dívidas e de seus ativos. Aparentemente simples, essa regra é de difícil aplicação, em face das imperfeições do mercado de capitais, tais como custos de agência, assimetria das informações, custos de transação, riscos de liquidez, impostos e efeitos de sinalização.

Além destes modelos teóricos, há ainda outros determinantes da estrutura de maturidade das dívidas, entre eles tamanho e crescimento da empresa, alavancagem, variação dos montantes e momento de emissão das dívidas, bem como participação dos administradores no capital da empresa.

Não obstante o progresso dos estudos sobre os determinantes da maturidade das dívidas no mundo, pouco se sabe sobre esse tema com relação às empresas brasileiras. Assim, o objetivo principal deste trabalho consiste em analisar os principais determinantes da estrutura de maturidade das dívidas, à luz das teorias baseadas nas imperfeições do mercado, bem como compreender o perfil do endividamento das empresas brasileiras de grande porte, detentoras de dívidas bancárias e emissoras de debêntures.

\section{Referencial Teórico}

Segundo Myers (1977), em sua teoria dos custos de agência, as dívidas de curto prazo mitigam o efeito do problema de subinvestimento. Este problema pode ocorrer nos casos em que os acionistas não têm incentivos para investir em projetos com valor presente líquido (VPL) positivo. Quando o nível de dívida é muito alto, os lucros residuais provavelmente são muito próximos de zero. Nesse caso, os grandes beneficiados nesses investimentos são os credores (Titman \& Wessels, 1988). Assim, ao emitir dívidas que vençam antes que a oportunidade de investimento expire, os acionistas podem pagar aos credores e manter toda a rentabilidade do projeto. De fato, os estudos empíricos de Aivazian, Ge e Qiu (2005) verificam que dívidas de longo prazo reduzem o investimento das empresas, em especial para aquelas com maiores perspectivas de crescimento. Significa dizer que empresas com maiores oportunidades de crescimento possuem mais dívidas de curto prazo (Highfield, Roskelley, \& Zhao, 2007).

Ao considerarmos os demais modelos teóricos de assimetria das informações, custos de transação, riscos de liquidez, impostos e efeitos de sinalização, todos apontam uma estrutura de dívidas com vencimentos preferencialmente mais curtos, em face de uma dada realidade das empresas com maior oportunidade de crescimento, altos níveis de assimetria de informações, baixo ou alto nível de risco de seus títulos e altas alíquotas de impostos. Assim sendo, segue abaixo uma breve descrição da relação entre as teorias acima mencionadas e a maturidade das dívidas.

\section{Custos de agência}

Os estudos de maturidade das dívidas que antecedem os de Myers (1977) afirmam que as dívidas podem criar problemas de incentivo aos acionistas. Ele argumenta que a emissão de dívidas de curto prazo pode resolver a questão do subinvestimento, por meio de sua maturação antes da 
oportunidade de realização das opções de crescimento. Assim, empresas com maiores oportunidades de crescimento irão empregar mais dívidas de curto prazo em sua estrutura de capital.

Para Yi (2005) as empresas com maiores oportunidades de investimentos futuros tendem a ser as de menor porte. Sua afirmação é baseada nos estudos de Smith e Warner (1979), que argumentam que empresas pequenas enfrentam um conflito potencial entre credores e acionistas, em função da assunção de riscos e diluição de direitos, o qual pode ser controlado com emissão de dívidas de curto prazo. Por sua vez, Ozkan (2000) argumenta que empresas maiores possuem menor custo de agência, devido à sua facilidade de acesso ao mercado de capitais. Ou seja, o tamanho da empresa e seu nível de risco podem ser considerados como fatores de retenção do problema de agência. "Os custos de agência sugerem que tomadores de dívidas em negócios arriscados possuem um incentivo a custos de agência menores via emissão de dívidas com maturidade menor" (Yi, 2005, p. 278).

De fato, estudos empíricos de Silva e Valle (2008), bem como Rochman, Eid e Laureano (2009) apresentaram sinal positivo entre tamanho da empresa e dívidas de longo prazo, enquanto os de Jiraporn e Kitsabunnarat (2007) indicam o seguinte: quando os interesses dos gestores se sobrepõem aos dos acionistas, essas empresas tendem a contrair mais dívidas de longo prazo.

Com base no acima exposto, tem-se isto: quanto maior os custos de agência, menor a maturidade das dívidas. Além disso, as empresas menores enfrentam mais problemas de agência (entre acionistas e credores) que as de grande porte. Logo, quanto menor o tamanho das empresas, menor a maturidade de suas dívidas.

\section{Assimetria da informação ou sinalização}

Tem sido sugerido por alguns autores que a estrutura de dívidas de uma empresa pode sinalizar as informações de dentro dela sobre sua qualidade. Por exemplo, Flannery (1986) aponta o fato de que gestores de empresas de alta qualidade emitem mais dívidas de curto prazo que aquelas de baixa qualidade. Emitindo dívidas de curto prazo, os gestores das empresas mais sólidas estão se submetendo ao risco de que elas sejam forçadas a refinanciar suas dívidas após novas informações.

Segundo Lucas e McDonald (1990), as empresas geralmente contemporizam para emitir suas dívidas, caso elas esperem um aumento no preço de suas ações devido às boas notícias; porém elas não farão o mesmo até as más notícias serem publicadas. Goswami (2000) reforça essa ideia, ao afirmar que, se existe assimetria da informação, com relação à qualidade dos ativos, uma empresa pode sinalizar a qualidade destes, via emissão de dívidas de curto prazo.

Kale e Noe (1990) mostram que esse mesmo resultado pode ser obtido sem a existência de custos de transação. Dessa forma, devido ao fato das dívidas de curto prazo poderem ser mais rapidamente reprecificadas, para refletir a nova informação; isso minimiza o problema da seleção adversa, por meio de nova emissão de dívidas. Dessa forma, na ausência do custo de transação ou de controles, todas as empresas utilizam dívidas de curto prazo.

Estudos empíricos de Silva e Valle (2008) encontraram sinais negativos entre a qualidade das empresas e o nível de maturidade das dívidas, além de coeficientes estatisticamente significativos a $1 \%$.

Segundo Yi (2005), outra forma de sinalização ao mercado se dá por meio do risco de liquidez de crédito, o que incentiva algumas empresas a contrair dívidas de longo prazo. Para Diamond (1991), a escolha da estrutura de maturidade das dívidas ocorre por meio de uma troca entre o desejo dos tomadores em emitir dívidas de curto prazo e o risco de liquidez de crédito inerente a esse tipo de financiamento. Em seu modelo, empresas de alta qualidade optam por emitir dívidas de curto prazo. Já as de baixa qualidade não têm outra alternativa que não a de contraírem dívidas apenas de curto prazo, devido ao risco de refinanciamento. Dessa forma, apenas as empresas de médio risco estão mais inclinadas a emitir dívidas de longo prazo. 
Berger, Espinosa-Vega, Frame e Miller (2005), ao testar o modelo de Diamond (1991) e Flannery (1986), encontraram significância estatística na hipótese de que empresas que possuem baixo nível de qualidade (alto nível de risco) possuem mais dívidas de curto prazo, e de que essa maturidade tende a aumentar, quando a assimetria informacional é reduzida.

Por sua vez, Smith (1986) argumenta que administradores de empresas com monitoramento possuem menos autonomia sobre decisões de investimentos futuros que nas empresas sem monitoramento. Para Barclay e Smith (1995), a falta de prudência dos administradores reduz o efeito do incentivo contrário da dívida de longo prazo. A hipótese do custo de contratação, portanto, implica que as empresas com monitoramento, como as que contraem dívidas junto aos bancos, têm uma maturidade maior de suas dívidas que as empresas que não o possuem.

Adicionalmente, Yi (2005) complementa, afirmando que empresas de alta qualidade com boa reputação tendem a emitir dívidas, enquanto empresas de média qualidade decidem-se por financiamentos bancários. Mesmo que o monitoramento não seja efetivo para as empresas de baixa qualidade, embora incorrendo em altos custos, estas tendem a contrair dívidas junto aos bancos. A afirmação existente, portanto, é esta: quanto maior a assimetria de informações, menor a maturidade das dívidas.

\section{Impostos}

É mostrado por Kane, Marcus e McDonald (1985) que a estrutura ótima de maturidade das dívidas é determinada por uma troca entre as vantagens tributárias do financiamento bancário versus o risco de falência e a flutuação dos custos de emissão de dívidas. Os autores verificam que a maturidade ótima das dívidas aumenta à medida que as vantagens tributárias das dívidas bancárias diminuem, que a flutuação dos custos de emissão de dívidas aumentam e que a volatilidade do valor da empresa diminui.

Segundo Ozkan (2000), a razão para a relação inversa entre as vantagens tributárias e a maturidade das dívidas, ou seja, o que motiva a empresa a aumentar a maturidade de suas dívidas, à medida que as vantagens tributárias destas diminuem, é a possibilidade de esta garantir que o benefício tributário restante de seus financiamentos não seja menor que a amortização da flutuação dos custos de emissão de dívidas.

Por sua vez, Brick e Ravid (1985) afirmam que a empresa escolhe seu nível de alavancagem antes da maturidade da dívida ser definida. Todavia, pode haver casos nos quais os tributos não possuem efeito na maturidade ótima das dívidas, sendo irrelevantes quando a alavancagem ótima e a maturidade da dívida forem escolhidas simultaneamente. Dessa forma, a hipótese tributária implica que há uma relação negativa entre maturidade das dívidas e as alíquotas tributárias corporativas. Referida hipótese foi ratificada pelos estudos empíricos de Highfield, Roskelley e Zhao (2007).

\section{Maturidade dos ativos (matching)}

Myers (1977) argumenta que o problema do subinvestimento é devido ao conflito de agência entre acionistas e credores das dívidas, e que este pode ser reduzido de tamanho pelo casamento entre maturidade dos ativos e passivos das empresas. O casamento (matching) das maturidades garante que o pagamento das dívidas será programado para corresponder ao declínio do valor dos ativos. Além disso, como explanado por Stohs e Mauer (1996), quando a maturidade de uma dívida é mais curta que a dos seus ativos, a empresa pode não ter caixa suficiente em mãos para pagar suas dívidas, quando elas vencerem.

Por outro lado, se a dívida tiver prazo maior que a maturidade dos ativos, então o fluxo de caixa dos ativos pode cessar, enquanto a empresa possui dívidas remanescentes que honrar. A implicação empírica é, portanto, que deve existir uma relação positiva entre maturidade das dívidas e dos ativos. 


\section{Risco de liquidez (alavancagem financeira)}

O modelo desenvolvido por Diamond (1991) identificou que o risco de liquidez está associado com as dívidas de curto prazo. Empresas com baixos níveis de alavancagem possuem baixo nível de risco de liquidez e de dívidas de curto prazo. Dessa forma, à medida que a alavancagem aumenta, também aumenta o risco de liquidez, e a maturidade das dividas.

\section{Síntese das teorias sobre a maturidade das dívidas}

A literatura produzida até então aponta as quatro hipóteses teóricas acima mencionadas, relacionadas aos determinantes da estrutura de maturidade das dívidas. As referidas hipóteses foram testadas por meio de alguns estudos empíricos, que foram desenvolvidos considerando as seguintes variáveis.

Tabela 1

\section{Síntese das Teorias sobre a Maturidade das Dívidas}

\begin{tabular}{|c|c|c|c|}
\hline $\begin{array}{c}\text { Teorias de } \\
\text { Imperfeições do } \\
\text { Mercado }\end{array}$ & $\begin{array}{c}\text { Hipóteses sobre a Maturidade das } \\
\text { Dívidas }\end{array}$ & Variáveis & Medida \\
\hline \multirow{2}{*}{ Custos de agência } & $\begin{array}{l}\text { Quanto maior é a oportunidade de } \\
\text { crescimento, menor é a maturidade } \\
\text { das dívidas. }\end{array}$ & Oportunidade & $\begin{array}{c}\text { Valor de Mercado/ Valor } \\
\text { Contábil }\end{array}$ \\
\hline & $\begin{array}{l}\text { Quanto menor é a empresa, menor é } \\
\text { a maturidade de suas dívidas. }\end{array}$ & Tamanho & $\begin{array}{c}\text { Valor de Mercado, Valor } \\
\text { Contábil e Receita } \\
\text { Operacional Líquida }\end{array}$ \\
\hline $\begin{array}{c}\text { Teorias de } \\
\text { Imperfeições do } \\
\text { Mercado }\end{array}$ & $\begin{array}{c}\text { Hipóteses sobre a Maturidade das } \\
\text { Dívidas }\end{array}$ & Variáveis & Medida \\
\hline \multirow{2}{*}{$\begin{array}{l}\text { Assimetria da } \\
\text { informação ou } \\
\text { sinalização }\end{array}$} & $\begin{array}{l}\text { Quanto melhor é a qualidade da } \\
\text { empresa, menor é a maturidade das } \\
\text { dívidas. }\end{array}$ & Qualidade & $\begin{array}{l}\text { Variação do Lucro por } \\
\text { Ação }\end{array}$ \\
\hline & $\begin{array}{l}\text { Quanto melhor ou pior é o rating da } \\
\text { empresa, menor é a maturidade das } \\
\text { dívidas. }\end{array}$ & Rating & $\begin{array}{l}\text { Escala de nacional de } \\
\text { rating empresarial } \\
\text { definido pela Standard \& } \\
\text { Poors (S\&P) }\end{array}$ \\
\hline \multirow{2}{*}{ Impostos } & $\begin{array}{c}\text { Quanto menor é a alíquota efetiva de } \\
\text { tributos, maior é a maturidade das } \\
\text { dívidas. }\end{array}$ & $\begin{array}{l}\text { Alíquota } \\
\text { Efetiva de } \\
\text { Tributos }\end{array}$ & $\begin{array}{l}\text { Despesa de IR/CS }(\div) \\
\text { Lucro Antes do IR/CS }\end{array}$ \\
\hline & $\begin{array}{c}\text { Quanto menor é a volatilidade do } \\
\text { valor dos ativos da empresa, maior é } \\
\text { a maturidade das dívidas. }\end{array}$ & $\begin{array}{l}\text { Volatilidade } \\
\text { dos ativos }\end{array}$ & $\begin{array}{c}\text { VAR }(\mathrm{s})= \\
\text { EBITDA/Valor Contábil } \\
\text { dos Ativos }\end{array}$ \\
\hline $\begin{array}{l}\text { Maturidade dos ativos } \\
\text { (Matching) }\end{array}$ & $\begin{array}{l}\text { Quanto maior for a maturidade dos } \\
\text { ativos, maior será maturidade dos } \\
\text { passivos. }\end{array}$ & $\begin{array}{l}\text { Maturidade } \\
\text { dos Ativos }\end{array}$ & $\begin{array}{l}\text { Média ponderada da } \\
\text { maturidade dos ativos } \\
\text { circulantes e imobilizado } \\
\text { líquido de depreciação }\end{array}$ \\
\hline Risco de liquidez & $\begin{array}{l}\text { Quanto maior é o nível de } \\
\text { alavancagem, maior é a maturidade } \\
\text { das dívidas. }\end{array}$ & Alavancagem & $\begin{array}{l}\text { Dívida total / Valor de } \\
\text { mercado dos ativos }\end{array}$ \\
\hline
\end{tabular}

Nota. Fonte: elaborado pelos autores. 
Assim, com base nos referenciais teóricos e estudos empíricos existentes, realizados fora do país, este trabalho pretende reproduzir tais análises, considerando unicamente empresas de grande porte, localizadas no Brasil, que possuam financiamentos bancários e/ou que emitam debêntures.

\section{Metodologia de Pesquisa}

\section{Hipóteses}

Para verificar a relação entre a estrutura de maturidade das dívidas das empresas brasileiras e os modelos teóricos relacionados às imperfeições de mercado - que constitui o objetivo central da pesquisa - é necessário testar as seguintes hipóteses.

Tabela 2

\section{Formulação de Hipóteses}

\begin{tabular}{|c|c|c|}
\hline Variáveis & & Hipóteses \\
\hline Oportunidade & $\mathrm{H} 1,1$ : & $\begin{array}{l}\text { Quanto maior é a oportunidade de crescimento (OPOCR) da empresa , menor é a } \\
\text { maturidade das dívidas (MATD). }\end{array}$ \\
\hline Tamanho & H1,2: & $\begin{array}{l}\text { Quanto maior é o tamanho da empresa (TAM), maior é a maturidade das dívidas } \\
\text { (MATD). }\end{array}$ \\
\hline Qualidade & H1,3: & $\begin{array}{l}\text { Quanto maior é a qualidade (QUAL) da empresa, menor é a maturidade das } \\
\text { dívidas (MATD). }\end{array}$ \\
\hline Rating & $\mathrm{H} 1,4$ : & $\begin{array}{l}\text { Quanto mais alto (RATA) ou mais baixo (RATB) é o rating das empresas, } \\
\text { menor a maturidade das dívidas (MATD). }\end{array}$ \\
\hline $\begin{array}{l}\text { Alíquota Efetiva } \\
\text { de Tributos }\end{array}$ & H1,5: & $\begin{array}{l}\text { Quanto maior é a alíquota efetiva de tributo (TAXE), menor a maturidade das } \\
\text { dívidas (MATD). }\end{array}$ \\
\hline $\begin{array}{l}\text { Volatilidade dos } \\
\quad \text { Ativos }\end{array}$ & H1,6: & $\begin{array}{l}\text { Quanto maior é a volatilidade dos ativos (VAR), menor a maturidade das dívidas } \\
\text { (MATD). }\end{array}$ \\
\hline $\begin{array}{l}\text { Maturidade dos } \\
\quad \text { Ativos }\end{array}$ & $\mathrm{H} 1,7$ : & $\begin{array}{l}\text { Quanto maior é a maturidade dos ativos (MATA), maior é a maturidade das } \\
\text { dívidas (MATD). }\end{array}$ \\
\hline Alavancagem & $\mathrm{H} 1,8$ : & $\begin{array}{l}\text { Quanto maior é a alavancagem (ALAV), maior é a maturidade das dívidas } \\
\text { (MATD). }\end{array}$ \\
\hline
\end{tabular}

Nota. Fonte: elaborado pelos autores.

\section{Descrição das variáveis das hipóteses}

\section{Maturidade das dívidas}

Por dívida junto a terceiros, compreendem-se empréstimos, financiamentos e debêntures. A variável de maturidade das dívidas é composta pela seguinte fórmula:

$$
\text { MATD }=\left[\left(\frac{P C-D C}{P C+E L P}\right) \times \text { MPC }\right]+\left[\left(\frac{E L P+D C}{P C+E L P}\right) \times \text { MELP }\right]
$$

Em que: 
MATD: Maturidade das dívidas; PC: Passivo circulante; DC: Dívidas do circulante; ELP: Exigível a longo prazo (parte-se do princípio de que mais de 50\% do ELP é representado por dívidas de longo prazo); MPC: Maturidade do passivo circulante; MELP: Maturidade do exigível a longo prazo.

Por sua vez, a maturidade do passivo circulante (MPC) é calculada com base na estimativa do tempo médio em que os passivos circulantes estão pendentes ao longo de um ano. O passivo circulante é uma fonte de financiamento da atividade operacional da empresa, cujo valor da produção é equivalente ao custo dos produtos vendidos (CPV).

Desta forma, ao se dividir o CPV pelo PC, tem-se o número de vezes, ao longo de um ano, que a empresa refinancia seu PC. O inverso dessa razão (MPC) é a proporção do ano nas quais as referidas obrigações de curto prazo estão pendentes, conforme equação 2 .

$$
M P C=\frac{P C}{C P V} \times 12 \text { meses }
$$

Já a maturidade das dívidas de longo prazo (MELP) é calculada por meio da seguinte fórmula:

$$
M E L P=\frac{\sum_{J}^{J} V_{J} M_{J}}{\sum_{J}^{J} V_{J}}
$$

Em que:

J: Quantidade de tipos de dívidas de longo prazo (empréstimos, financiamentos e/ou debêntures); V: Valor em R \$ das dívidas de longo prazo; M: Maturidade restante das dívidas de longo prazo.

\section{Custos de agência}

\section{Oportunidades de crescimento}

As oportunidades de crescimento (OPOCR) são representadas pela razão entre o valor de mercado dos ativos da empresa (VMA), em relação ao valor contábil do total dos ativos (VCA).

$$
O P O C R=\frac{V M A}{V C A}
$$

Por sua vez, o valor de mercado dos ativos (VMA) é estimado como o valor contábil dos ativos (VCA), mais a diferença entre o valor de mercado (VMPL) e o valor contábil (VCPL) do patrimônio líquido: $V M A=V C A+(V M P L-V C P L)$.

Já o valor de mercado do PL é obtido pela multiplicação entre a quantidade de ações e seu valor de negociação na Bolsa de Valores $\Rightarrow V M P L=$ Quantidadex Cotaçãodas Ações

Smith e Watts (1992) argumentam que quanto maior a oportunidade de crescimento, maior a razão entre seu valor de mercado e seu valor contábil. Desta maneira, espera-se uma relação inversa entre MATD e VMA/VCA. 
2. Tamanho da empresa

O tamanho da empresa (TAM) é medido pelo logaritmo natural ou neperiano $\left(\log _{e}^{x}=1\right.$, em que e $=2,718281828$ ) da estimativa de seu : Valor de mercado dos ativos (LNVMA); Valor contábil dos ativos (LNVCA); Receita operacional líquida (LNROL); Patrimônio Líquido (LNPL)

\section{Assimetria da informação ou sinalização}

1. Qualidade da empresa

As pessoas internas das empresas conseguem antecipar mudança na qualidade (QUAL) da mesma por meio das mudanças de ganhos futuros, ou seja, por meio da variação do lucro por ação (LPA), que é a diferença entre o LPA do próximo ano, em relação ao atual (equação 5).

$$
Q U A L=\Delta L P A=\frac{L P A_{t+1}}{L P A_{t}}
$$

O modelo de sinalização de Flannery (1986) prevê uma relação negativa entre MATD e QUAL.

2. Rating das debêntures das empresas

Diamond (1991) afirma que empresas com ratings muito altos e baixos contraem dívidas no curto prazo, enquanto empresas com ratings médios possuem dívidas de longo prazo. Para testar essa relação entre ratings e maturidade das dívidas, foi considerada uma tabela na qual foram atribuídos números de 1 a 21 para a escala nacional de ratings (RAT) empresariais de curto e longo prazo da Standard \& Poor's, onde $1=$ AAA e $21=$ D.

Os ratings empresariais da escala nacional Brasil Standard \& Poor's é uma opinião atualizada da capacidade creditícia geral de um emissor de dívida de que honre suas obrigações financeiras no devido prazo, em comparação com outros devedores brasileiros. Para os anos em que a empresa não possuía rating, calculou-se uma média aritmética dos demais anos.

Assim, foram definidos três intervalos de ratings, conforme abaixo:

Tabela 3

Intervalos de Ratings

\begin{tabular}{cccc}
\hline Nível & Rating & No. & Descrição \\
\hline Alto & brAAA & 1 & $\begin{array}{l}\text { Um devedor com um rating 'brAAA' possui capacidade MUITO FORTE de } \\
\text { honrar seus compromissos financeiros em relação a outros devedores brasileiros. } \\
\text { O Rating Empresarial 'brAAA' é o mais alto atribuído pela Escala Nacional } \\
\text { Brasil Standard \& Poor's. }\end{array}$ \\
Alto & brAA+ & 2 & \\
Alto & brAA & 3 & $\begin{array}{l}\text { Um devedor com um rating 'brAA' difere pouco dos devedores com os ratings } \\
\text { mais altos, e possui uma capacidade FORTE de honrar seus compromissos } \\
\text { financeiros, em relação a de outros devedores brasileiros. }\end{array}$ \\
Alto & brAA- & 4 & \\
Médio & brA+ & 5 &
\end{tabular}

Continua 
Tabela 3 (continuação)

\begin{tabular}{|c|c|c|c|}
\hline Nível & Rating & No. & Descrição \\
\hline Médio & brA & 6 & $\begin{array}{l}\text { Um devedor com um rating 'brA' está mais suscetível aos efeitos adversos } \\
\text { trazidos por mudanças nas condições econômicas, quando comparado a outros } \\
\text { devedores com ratings mais altos. Mesmo assim, esse devedor apresenta } \\
\text { capacidade RAZOAVELMENTE FORTE de honrar suas obrigações } \\
\text { financeiras, em relação a outros devedores brasileiros. }\end{array}$ \\
\hline Médio & brA- & 7 & \\
\hline Médio & brBBB+ & 8 & \\
\hline Médio & brBBB & 9 & $\begin{array}{l}\text { Um devedor que recebe um rating 'brBBB' possui capacidade ADEQUADA de } \\
\text { honrar seus compromissos financeiros em relação a outros devedores brasileiros. } \\
\text { Porém, condições econômicas adversas ou outras circunstâncias, muito } \\
\text { provavelmente, levarão à redução de sua capacidade de honrar suas obrigações } \\
\text { financeiras. }\end{array}$ \\
\hline Nível & Rating & No. & Descrição \\
\hline Médio & brBBB- & 10 & \\
\hline Médio & brBB+ & 11 & \\
\hline Médio & brBB & 12 & $\begin{array}{l}\text { Um devedor com um rating 'brBB' apresenta-se MENOS VULNERÁVEL, no } \\
\text { curto prazo, do que devedores brasileiros com ratings mais baixos. Porém ele } \\
\text { enfrenta incertezas ou exposição a condições comerciais, financeiras ou } \\
\text { econômicas adversas, que poderiam resultar em uma capacidade inadequada, do } \\
\text { devedor de cumprir suas obrigações financeiras. }\end{array}$ \\
\hline Médio & brBB- & 13 & \\
\hline Médio & brB+ & 14 & \\
\hline Médio & brB & 15 & $\begin{array}{l}\text { Um devedor com um rating 'brB' está MAIS VULNERÁVEL do que outros } \\
\text { devedores com ratings 'brBB'. O devedor atualmente apresenta capacidade de } \\
\text { cumprir seus compromissos financeiros, em relação a outros devedores } \\
\text { brasileiros. Condições comerciais, financeiras ou econômicas adversas } \\
\text { provavelmente interfeririam na sua capacidade ou disponibilidade de cumprir } \\
\text { suas obrigações financeiras. }\end{array}$ \\
\hline Médio & brB- & 16 & \\
\hline Baixo & brCCC & 17 & $\begin{array}{l}\text { Um devedor com um rating 'brCCC' apresenta-se ATUALMENTE } \\
\text { VULNERÁVEL, e depende de condições comerciais e financeiras favoráveis } \\
\text { para honrar seus compromissos financeiros, quando comparado a outros } \\
\text { devedores brasileiros. }\end{array}$ \\
\hline Baixo & brCC & 18 & $\begin{array}{l}\text { Um devedor com um rating 'brCC' está ATUALMENTE MUITO } \\
\text { VULNERÁVEL à inadimplência, quando comparado a outros devedores } \\
\text { brasileiros. }\end{array}$ \\
\hline Baixo & brR & 19 & $\begin{array}{l}\text { Um devedor com um rating de 'brR' está sob supervisão regulamentar, devido às } \\
\text { suas condições financeiras. Durante a pendência da supervisão regulamentar, os } \\
\text { reguladores podem favorecer uma classe de obrigações ao invés de outra. Para } \\
\text { obter uma descrição mais detalhada dos efeitos da supervisão regulamentar em } \\
\text { emissões ou classes de obrigações específicas, favor consultar os ratings de } \\
\text { dívidas da Standard \& Poor's. }\end{array}$ \\
\hline
\end{tabular}

Continua 
Tabela 3 (continuação)

\begin{tabular}{cccc}
\hline Nível & Rating & No. & \multicolumn{1}{c}{ Descrição } \\
\hline Baixo & brSD & 20 & $\begin{array}{l}\text { Um rating 'brSD' é atribuído quando a Standard \& Poor's acredita que o devedor } \\
\text { foi seletivo no não pagamento de uma obrigação específica ou classe de } \\
\text { obrigações, porém continuará a honrar o pagamento de outras emissões ou } \\
\text { classes de obrigações nos prazos estabelecidos. }\end{array}$ \\
\hline Nível & Rating & No. & \multicolumn{1}{c}{ Descrição } \\
\hline Baixo & brD & 21 & $\begin{array}{l}\text { Um rating 'brD' é atribuído quando a Standard \& Poor's acredita que a } \\
\text { inadimplência será geral e o devedor não pagará todas ou quase todas as suas } \\
\text { obrigações no prazo devido. }\end{array}$ \\
\hline
\end{tabular}

Nota. Fonte: elaborado pelos autores.

Realizou-se 2 tipos de testes. No primeiro, para as empresas localizadas nos níveis de rating alto (RATA) e baixo (RATB), espera-se baixo nível de maturidade das suas dívidas (MATD). Para as empresas localizadas no nível médio de rating (RATM), espera-se um alto nível de maturidade das dívidas (MATD).

No segundo teste, foram utilizadas variáveis dummy para os ratings. Debênture com rating baixo (RATB) é igual a 1. Isto é, ele deve ser igual ou abaixo de CCC. Caso o rating seja diferente disto, o mesmo é igual a zero (0). Por sua vez, debênture com rating alto (RATA) é igual a 1. Isto é, ele deve ser igual ou acima de AA. Caso o rating seja diferente disto, ele é igual a zero (0). É esperada uma relação negativa entre MATD e ambos RATB e RATA.

\section{Impostos}

1. Alíquota de tributos

A alíquota efetiva de tributos (TAXE) é calculada pela razão entre Despesa de IR/CS e Lucro Antes do IR/CS (LAIR). A literatura sobre a estrutura de maturidade das dívidas, baseada em tributos prevê uma relação negativa entre MATD e TAXE.

$$
T A X E=\frac{\text { Despesa IR } / C S}{L A I R}
$$

2. Variação dos ativos da empresa

O modelo de Kane et al. (1985) prevê que a maturidade das dívidas varia inversamente da volatilidade do valor dos ativos da empresa. A variável que representa a volatilidade (VAR) refere-se ao desvio-padrão da diferença entre o lucro antes de juros, impostos, depreciação e amortização (EBITDA) e o valor contábil dos ativos (VCA) de um ano em relação ao outro.

$$
\operatorname{VAR}(s)=d p\left[\left(\frac{E B I T D A}{V C A}\right)_{t}-\left(\frac{E B I T D A}{V C A}\right)_{t-1}\right]
$$

Espera-se uma relação negativa entre MATD e VAR. 


\section{Maturidade dos ativos (Matching)}

A teoria de Matching prevê um casamento entre a maturidade das dívidas e dos ativos. A maturidade dos ativos é medida por meio da média ponderada das maturidades dos ativos circulantes e dos ativos imobilizados líquidos da depreciação.

A maturidade dos ativos circulantes é obtida por meio da razão entre os ativos circulantes e o custo dos produtos vendidos. O raciocínio desta medida é baseado na noção de que os ativos circulantes (ex: estoques) suportam a produção; esta é medida pelo custo dos produtos vendidos.

Já a maturidade dos ativos imobilizados líquidos da depreciação é obtida pela razão entre os ativos imobilizados líquidos da depreciação e a despesa anual de depreciação. O raciocínio desta medida é que o critério de depreciação linear, o qual é usado no Balanço Patrimonial, que provê melhor aproximação da depreciação econômica do que o critério de depreciação acelerada que as empresas usam por propósitos tributários.

Por sua vez, a média ponderada é obtida pela participação dos ativos circulantes (AC) e do imobilizado líquido de depreciação, em relação à soma dos Ativos Circulantes (AC) e Imobilizado Líquido de Depreciação (IMlidD)

$$
M A T A=\left(\frac{A C}{C P V} \times \frac{A C}{A C+I M l i q D}\right)+\left(\frac{I M l i q D}{D D} \times \frac{\text { IMlidD }}{A C+I M l i q D}\right)
$$

Em que:

MATA: Maturidade dos ativos; AC: Ativo circulante; CPV: Custo dos produtos vendidos; IMLiqD: Imobilizado líquido de depreciação; DD: Despesa de depreciação.

É esperada uma relação positiva entre MATD e MATA.

\section{Alavancagem Financeira}

A medida de alavancagem foi incluída como variável de controle. Todavia, é razoável esperar uma relação positiva entre a maturidade das dívidas e a alavancagem. O modelo de Diamond (1991) prevê que os riscos de liquidez aumentam com a alavancagem. Assim sendo, empresas com alto nível de alavancagem devem ter mais dívidas de longo prazo, sendo o oposto igualmente verdadeiro.

A variável alavancagem (ALAV) é obtida por meio da razão entre o total das dívidas (DIVT) de curto e longo prazos - e o valor de mercado dos ativos (VMA) estimado. Por sua vez, as dívidas de curto e longo prazo são formadas por empréstimos, financiamentos e debêntures.

$$
A L A V=\frac{D I V T}{V M A}
$$

\section{População, amostra e coleta de dados}

As populações de interesse deste trabalho são as empresas no Brasil que possuam dívidas bancárias e/ou que emitam debêntures. Estas foram analisadas por meio de uma amostragem não probabilística intencional, ou seja, onde seus elementos são escolhidos.

O critério de definição das empresas da amostra iniciou-se pela identificação de 84 empresas que tinham seu risco de crédito avaliado pela empresa Standard \& Poor's entre 2002 e 2007. Destas, buscou-se identificar aquelas que, além da classificação de rating, possuíam os demais dados analisados pelas variáveis do modelo de regressão e não eram instituições financeiras. 
Considerando essas duas condições, foram selecionadas 38 empresas, cujos dados foram disponibilizados pelas fontes e nos períodos abaixo mencionados, estando associados às seguintes variáveis.

Tabela 4

Definição das Variáveis, Fonte e Período

\begin{tabular}{|c|c|c|c|}
\hline & Variáveis & Fonte & $\begin{array}{l}\text { Período de } \\
\text { cálculo }\end{array}$ \\
\hline \multirow{5}{*}{$\begin{array}{l}\text { Maturidade das dívidas } \\
\text { (MATD) }\end{array}$} & Passivo circulante (PC) & Economática & 2002 a 2007 \\
\hline & Dívidas do circulante (DC) & Economática & 2002 a 2007 \\
\hline & Exigível a longo prazo (ELP) & Economática & 2002 a 2007 \\
\hline & $\begin{array}{l}\text { Maturidade do passivo circulante } \\
\text { (MPC) }\end{array}$ & Economática & 2002 a 2007 \\
\hline & $\begin{array}{l}\text { Maturidade do exigível a longo } \\
\text { prazo (MELP) }\end{array}$ & $\begin{array}{l}\text { Economática e CVM } \\
\text { (Notas Explicativas) }\end{array}$ & 2002 a 2007 \\
\hline \multirow[t]{3}{*}{ Oportunidade (OPOCR) } & $\begin{array}{l}\text { Valor de Mercado dos Ativos } \\
\text { (VMA) }\end{array}$ & Economática & 2002 a 2007 \\
\hline & Valor Contábil dos Ativos (VCA) & Economática & 2002 a 2007 \\
\hline & $\begin{array}{l}\text { Logaritmo Neperiano do Valor de } \\
\text { Mercado dos Ativos (LNVMA) }\end{array}$ & Economática & 2002 a 2007 \\
\hline \multirow{2}{*}{ Tamanho (TAM) } & $\begin{array}{l}\text { Logaritmo Neperiano do Valor } \\
\text { Contábil dos Ativos (LNVCA) }\end{array}$ & Economática & 2002 a 2007 \\
\hline & $\begin{array}{l}\text { Logaritmo Neperiano da Receita } \\
\text { Operacional Líquida (LNROL) }\end{array}$ & Economática & 2002 a 2007 \\
\hline \multirow[b]{2}{*}{ Qualidade (QUAL) } & $\begin{array}{l}\text { Logaritmo Neperiano do Patrimônio } \\
\text { Líquido (LNPL) }\end{array}$ & Economática & 2002 a 2007 \\
\hline & $\begin{array}{l}\text { Variação do Lucro por Ação } \\
(\triangle \mathrm{LPA})\end{array}$ & Economática & 2002 a 2007 \\
\hline \multirow{2}{*}{ Rating (RAT) } & Rating Alto (RATA) & $\begin{array}{l}\text { Escala nacional de } \\
\text { ratings empresariais } \\
\text { de curto e longo } \\
\text { prazos da Standard \& } \\
\text { Poor's }\end{array}$ & 2002 a 2007 \\
\hline & Rating Baixo (RATB) & $\begin{array}{l}\text { Escala nacional de } \\
\text { ratings empresariais } \\
\text { de curto e longo } \\
\text { prazos da Standard \& } \\
\text { Poor's }\end{array}$ & 2002 a 2007 \\
\hline \multirow{2}{*}{$\begin{array}{l}\text { Alíquota Efetiva de } \\
\text { Tributos (TAXE) }\end{array}$} & Despesa de IR/CS & Economática & 2002 a 2007 \\
\hline & Lucro Antes do IR/CS (LAIR) & Economática & 2002 a 2007 \\
\hline \multirow[t]{2}{*}{$\begin{array}{l}\text { Volatilidade dos Ativos } \\
\text { (VAR) }\end{array}$} & $\begin{array}{l}\text { Lucro antes dos Impostos, } \\
\text { Depreciação e Amortização } \\
\text { (EBITDA) }\end{array}$ & Economática & 1999 a 2007 \\
\hline & Valor Contábil dos Ativos (VCA) & Economática & 1999 a 2007 \\
\hline
\end{tabular}


Tabela 4 (continuação)

\begin{tabular}{cccc}
\hline & \multicolumn{1}{l}{ Variáveis } & Fonte & $\begin{array}{c}\text { Período de } \\
\text { cálculo }\end{array}$ \\
\hline \multirow{2}{*}{$\begin{array}{c}\text { Maturidade dos Ativos } \\
\text { (MATA) }\end{array}$} & $\begin{array}{c}\text { Ativo Circulante (AC) } \\
\text { Imobilizado Líquido de Depreciação } \\
\text { (IMLiqD) }\end{array}$ & Economática & 2002 a 2007 \\
& Despesa de Depreciação (DD) & Economática & 2002 a 2007 \\
& Dívidas Totais (DIVT) & Economática & 2002 a 2007 \\
Alavancagem (ALAV) & Economática & 2007 a 2007 \\
& Valor de Mercado dos Ativos & Economática & 2002 a 2007 \\
\hline
\end{tabular}

Nota. Fonte: elaborado pelos autores

\section{Modelos estatísticos utilizados}

As associações referentes às hipóteses de pesquisa devem ser testadas por meio de regressão linear múltipla (cross section e dados em painel).

Neste trabalho, a variável dependente corresponde ao nível de maturidade das dívidas (MATD) e as variáveis independentes são OPOCR, TAM, QUAL, RATA, RATB, TAXE, VAR, MATA e ALAV.

$$
\begin{aligned}
& M_{A T D_{i}}=a+b \mathrm{OPOCR}_{i}+c T A M_{i}+d Q U A L_{i}+e \mathrm{RATA}_{i}+f \mathrm{RATB}_{i}+g T A X E_{i}+ \\
& h \mathrm{VAR}_{i}+i \mathrm{MATA}_{i}+j A L A V_{i}+u_{i}
\end{aligned}
$$

Em que:

MATD $:$ Variável dependente da $i$-ésima observação; OPOCR $_{\mathrm{i}}, \mathrm{TAM}_{\mathrm{i}}, \mathrm{QUAL}_{\mathrm{i}}, \mathrm{RATA}_{\mathrm{i}}, \mathrm{RATB}_{\mathrm{i}}$, TAXE $_{\mathrm{i}}, \mathrm{VAR}_{\mathrm{i}}, \mathrm{MATA}_{\mathrm{i}}$ e $\mathrm{ALAV}_{\mathrm{i}}$ : Variáveis independentes da $i$-ésima observação; $\mathrm{u}_{\mathrm{i}}$ : Termo de erro estocástico.

Entretanto, considerando uma análise específica para cada ano, será utilizado o método de regressão com dados em painel. Segundo Stock e Watson (2004), este método também é útil para controle de alguns tipos de variáveis omitidas, onde cada entidade é observada em dois ou mais períodos de tempo. Pelo estudo de variações na variável dependente ao longo do tempo, é possível eliminar o efeito das variáveis omitidas que diferem entre as entidades, mas são constantes ao longo do tempo.

Para Wooldridge (2006), o modelo de efeitos fixos leva em consideração as características únicas de cada unidade (empresa) do corte transversal, fazendo variar o intercepto para cada unidade, considerando, no entanto, que os coeficientes angulares são constantes entre unidades. Seus estimadores também são obtidos pelos Mínimos Quadrados Ordinários (Ordinary Least Squares [OLS]). Assim, o modelo proposto [11] é:

$$
\begin{aligned}
& M_{A T D_{i t}}=a_{i}+b O P O C R_{i t}+c T A M_{i t}+d Q U A L_{i t}+e R A T A_{i t}+f R A T B_{i t}+g \\
& T A X E_{i t}+h V A R_{i t}+i M A T A_{i t}+j A L A V_{i t}+u_{i t}
\end{aligned}
$$

O subscrito $i$ no termo de intercepto capta as diferenças entre as unidades (empresas) analisadas. Tais diferenças podem ser decorrentes das características especiais de cada empresa.

Já o modelo de efeitos aleatórios ou modelo de correção de erros trata o intercepto de uma unidade individual como extração aleatória da população muito maior com valor médio constante. $\mathrm{O}$ intercepto individual é, então, expresso como o desvio de seu valor médio constante. O método mais 
apropriado (melhor estimador linear não viesado), nesse caso, é o método por Mínimos Quadrados Generalizados (Generalized Least Squares [GLS]). O modelo é representado pela equação [12]:

$$
\begin{aligned}
& M_{A T D}=a+b O P O C R_{i t}+c T A M_{i t}+d Q U A L_{i t}+e R A T A_{i t}+f R A T B_{i t}+g \\
& T A X E_{i t}+h V A R_{i t}+i M A T A_{i t}+j A L A V_{i t}+\varepsilon_{i}+u_{i t}
\end{aligned}
$$

O termo de erro composto consiste em dois elementos: $\varepsilon_{i}$ que é o elemento do corte transversal ou específico dos indivíduos (empresas) não observável e $u_{i t}$ que é o elemento combinado da série temporal e do corte transversal.

\section{Análise dos Resultados}

Para realizar os testes estatísticos, foram utilizados os softwares SPSS v.17 e GRETL v. 1.9.1 de 24 de junho de 2010.

\section{Estatística descritiva}

A Tabela 5 apresenta a estatística descritiva das 38 empresas da amostra, considerando a média dos 6 anos de cada variável de regressão.

Tabela 5

Estatísticas Descritivas, Utilizando as Observações entre 2002 e 2007

\begin{tabular}{cc|cc}
\hline Variáveis & Média & Variáveis & Média \\
\hline MATD & 6,0263 & RATA &, 3684 \\
OPOCR & 1,3745 & RATB &, 0789 \\
LNVMA & 16,9474 & TAXE &, 3621 \\
LNVCA & 15,5526 & MATA & 6,1579 \\
LNROL & 14,7368 & ALAV &, 2295 \\
LNPL & 14,5000 & VAR &, 0547 \\
QUAL &, 5237 & & \\
\hline
\end{tabular}

Nota. Fonte: elaborada pelos autores.

As empresas apresentam uma maturidade média de suas dívidas de 6,02 anos, contra 6,15 anos de seus ativos, o que significa uma proximidade no casamento dos prazos. As variáveis de tamanho apresentam valores semelhantes entre si, o que caracteriza a possibilidade de substituição entre si sem perda de representatividade. Observa-se que entre elas, a que possui maior desvio padrão é a de valor de mercado dos ativos $(2,03944)$, sendo forte candidata a ser excluída do modelo de regressão. A alíquota efetiva de tributos é de $36 \%$ e o índice de alavancagem das dívidas é $23 \%$.

\section{Validação dos pressupostos do modelo de regressão cross section}

1. Normalidade

O pressuposto da normalidade dos resíduos pode ser verificado por meio da análise de sua média, que é próxima a zero. Além disso, essa análise pode ser igualmente realizada por meio dos gráficos das distribuições de probabilidade dos resíduos (Hair, Black, Babin, Anderson, \& Tatham, 2009). 


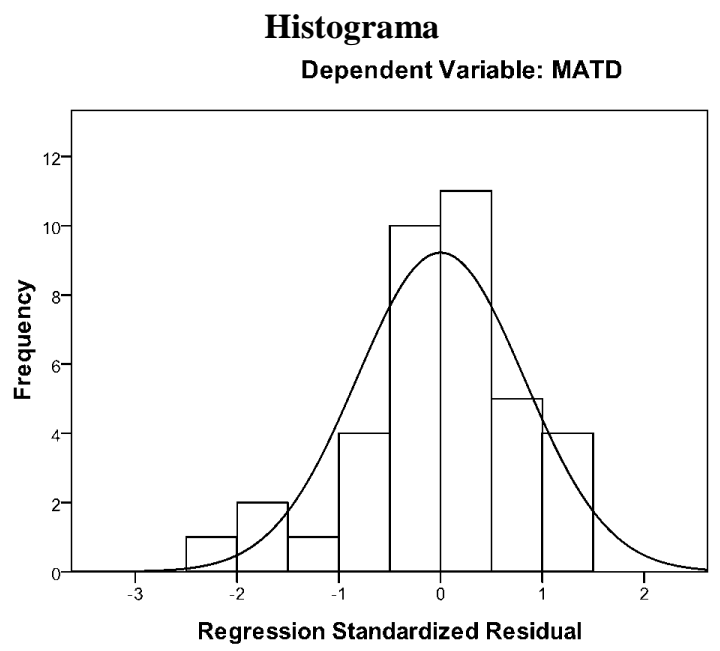

Distribuição de probabilidade Dependent Variable: MATD

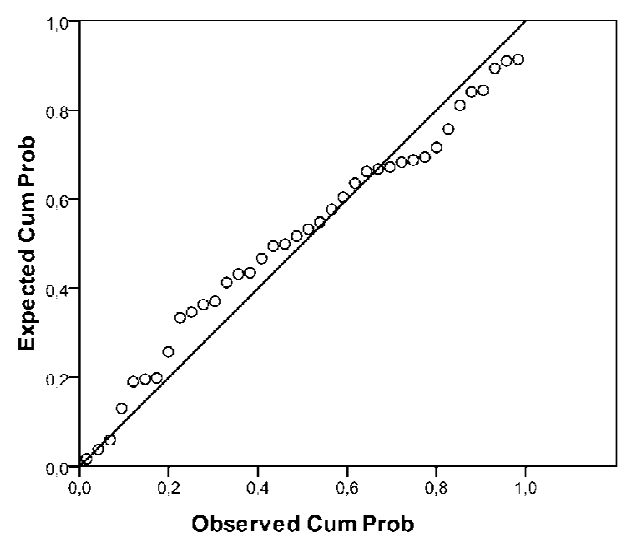

Figura 1. Normalidade dos Resíduos Fonte: elaborada pelos autores.

Os gráficos da Figura 1 mostram que os resíduos da regressão que tiveram como variável dependente a maturidade das dívidas (MATD) seguem distribuições de probabilidade aproximadamente normais. Por fim, sendo H0: o erro tem distribuição normal, a estatística de teste apresenta qui-quadrado $\left(\mathrm{X}^{2}\right)=1,08686$, com $p$-valor $=0,580752$. Logo, não rejeita-se H0.

\section{Multicolinearidade}

Duas das medidas mais comuns para avaliar a colinearidade de duas ou mais variáveis são o valor de Tolerância e seu inverso - o Fator de Inflação de Variância (FIV). Tolerância é a quantidade de variabilidade independente selecionada não explicada pelas outras variáveis independentes. Logo, valores muito pequenos de tolerância e muito grandes de FIV denotam multicolinearidade elevada, onde FIV $=\frac{1}{\text { tolerância }}$ (Gujarati, 2006).

Com base no teste $t$ dos coeficientes, verifica-se que apenas as variáveis LNPL $(17,923)$, LNVCA $(14,697)$ e LNMVA $(10,09)$ possuem alto nível de multicolinearidade, Significa dizer que a variável tamanho (TAM) será representada pelo Logaritmo Neperiano da Receita Operacional Líquida (LNROL). Quanto às demais variáveis independentes, os testes indicam que não houve violação do pressuposto da inexistência de multicolinearidade, uma vez que seu FIV é inferior a 5 e seu nível de tolerância é superior a 0,22 .

A análise da multicolinearidade também pode ser confirmada por meio da matriz de correlações que mostra que as variáveis independentes não estão altamente correlacionadas entre si, com exceção das variáveis de tamanho LNVMA, LNVCA, LNROL E LNPL - acima de 70\%.

\section{Autocorrelação}

A validade do pressuposto de independência dos resíduos foi analisada por meio do teste de Durbin-Watson. Considerando uma amostra de 38 empresas e 12 variáveis independentes $(\mathrm{k})$, em nível de significância de 5\%, as estatísticas obtidas na tabela 5 são: $d=1,51, d_{I}$ (inferior) $=0,796$ e $d_{S}$ (superior) $=2,351$. Esses valores apontam uma zona de indecisão, pois $0,796 \leq 1,51 \leq 2,351$ ou $d_{I} \leq d \leq d_{S}$ (Gujarati, 2006). Uma análise mais rigorosa implica que a $\mathrm{H}_{0}$ : Ausência de autocorrelação positiva ou negativa não pode ser aceita ou rejeitada. Entretanto, como a estatística $d$ de DurbinWatson está próxima a 2, considera-se ausência de autocorrelação significativa entre os resíduos. 


\section{Homoscedasticidade}

O pressuposto da homoscedasticidade dos resíduos foi avaliado por meio dos testes de White e Breusch- Pagan. No teste de White, H0 indica ausência de heteroscedasticidade. Como o $p$-valor = $\mathrm{P}($ Chi-Square $(22)>26,3577)=0,236642$, não rejeita-se H0. Por sua vez, o teste de Breusch-Pagan, H0 indica ausência de heteroscedasticidade. Como o p-valor $=\mathrm{P}($ Chi-Square $(12)>11,4456)=$ 0,491168 , não rejeita-se $\mathrm{H} 0$.

\section{Resultados de regressão cross section}

O modelo de regressão linear foi, inicialmente, analisado pelo método Enter, onde todas as variáveis independentes são consideradas. Neste caso, considerou-se a média entre os 6 anos de análise (2002 a 2007). Os resultados estão apresentados na Tabela 6 :

Tabela 6

Resultados MQO de Regressão pelo Método Enter

\begin{tabular}{|c|c|c|c|c|}
\hline & Coeficiente & Erro Padrão & razão-t & p-valor \\
\hline const & 26,0348 & 8,0598 & 3,2302 & $0,00315^{* * *}$ \\
\hline OPOCR & 0,6567 & 0,2021 & 3,2481 & $0,00301 * * *$ \\
\hline LNROL & $-1,2119$ & 0,4988 & $-2,4294$ & $0,02179^{* *}$ \\
\hline QUAL & 0,0092 & 0,6145 & 0,0150 & 0,98813 \\
\hline RATA & $-0,0116$ & 0,2337 & $-0,0499$ & 0,96056 \\
\hline RATB & $-0,0194$ & 0,4454 & $-0,0437$ & 0,96548 \\
\hline TAXE & $-2,5916$ & 0,6087 & $-4,2575$ & $0,00021 * * *$ \\
\hline MATA & $-0,1456$ & 0,0824 & $-1,7667$ & $0,08817^{*}$ \\
\hline ALAV & $-4,5431$ & 1,8918 & $-2,4014$ & $0,02322^{* *}$ \\
\hline VAR & $-1,9522$ & 2,3933 & $-0,8157$ & 0,42156 \\
\hline Média var. dependente & 6,03626 & \multicolumn{2}{|c|}{ D.P. var. dependente } & 1,05681 \\
\hline Soma resíd. quadrados & 10,54176 & \multicolumn{2}{|c|}{ E.P. da regressão } & 0,61358 \\
\hline R-quadrado & 0,74490 & \multicolumn{2}{|c|}{ R-quadrado ajustado } & 0,66290 \\
\hline $\mathrm{F}(9,28)$ & 9,08455 & \multicolumn{2}{|c|}{ P-valor (F) } & $2,83 \mathrm{e}-06$ \\
\hline Log da verossimilhança & $-29,55706$ & \multicolumn{2}{|c|}{ Critério de Akaike } & 79,11413 \\
\hline Critério de Schwarz & 95,48999 & \multicolumn{2}{|c|}{ Critério Hannan-Quinn } & 84,94054 \\
\hline
\end{tabular}

Nota.*** Significante ao nível de 1\%; ** Significante ao nível de 5\%; * Significante ao nível de $10 \%$.

Fonte: Elaborada pelos autores.

As variáveis independentes que possuem melhor nível de significância são: (a) Oportunidades de crescimento (OPOCR) e Alíquota efetiva de tributos (TAXE), com nível de significância menor de 1\%; (b) Logaritmo neperiano da receita operacional líquida (LNROL) e Alavancagem (ALAV), com nível de significância entre de 5\% e (c) Maturidade dos ativos (MATA), com nível de significância de $10 \%$. As demais variáveis apresentam correlação muito fraca e não significante (>10\%).

Com relação aos sinais esperados das variáveis que possuem um nível de significância aceitável, apenas a variável TAXE se comporta conforme a teoria mencionada. Significa dizer que as variáveis OPOCR, LNROL, ALAV e MATA, apesar de significantes, não se relacionam com a variável dependente maturidade das dívidas (MATD), conforme teoria apresentada. 
Quanto aos resultados de todo o modelo de regressão, o coeficiente ajustado de determinação $\left(\mathrm{R}^{2}\right.$ ajustado) é significativamente maior do que zero $(0,66)$. Por sua vez, de acordo com a estatística $\mathrm{F}$, pode-se explicar 9 vezes mais do que quando usamos a média e isso não tem muita probabilidade de ocorrer (menos que $1 \%$ das vezes ).

\section{Resultados de regressão com dados em painel}

No modelo de regressão com dados em painel, empregando a abordagem de efeitos fixos, observa-se que apenas a variável MATA possui resultado significante e contrário ao que prediz a teoria, de acordo com a Tabela 7.

Tabela 7

Resultados Dados em Painel com Efeitos-Fixos

\begin{tabular}{|c|c|c|c|c|}
\hline & Coeficiente & Erro Padrão & razão-t & p-valor \\
\hline const & 5,9622 & 6,6373 & 0,8983 & 0,3702 \\
\hline OPOCR & $-0,2634$ & 0,1719 & $-1,5320$ & 0,1272 \\
\hline LNROL & 0,1775 & 0,4432 & 0,4007 & 0,6891 \\
\hline QUAL & $-0,3337$ & 0,2797 & $-1,1931$ & 0,2344 \\
\hline RATA & 0,5025 & 0,5506 & 0,9126 & 0,3627 \\
\hline RATB & $-0,3602$ & 0,9884 & $-0,3644$ & 0,7160 \\
\hline TAXE & $-0,2315$ & 0,3153 & $-0,7344$ & 0,4636 \\
\hline MATA & $-0,3067$ & 0,0715 & $-4,2881$ & $2,93 \mathrm{e}-05^{* * *}$ \\
\hline ALAV & $-1,1195$ & 0,9047 & $-1,2372$ & 0,2175 \\
\hline VAR & - 1,6425 & 2,8339 & $-0,5796$ & 0,5629 \\
\hline Média var. dependente & \multicolumn{2}{|c|}{5,54206} & dependente & 2,81172 \\
\hline Soma resíd. quadrados & \multicolumn{2}{|c|}{630,1324} & regressão & 1,86585 \\
\hline R-quadrado & \multicolumn{2}{|c|}{0,64887} & do ajustado & 0,55963 \\
\hline$F(46,181)$ & \multicolumn{2}{|c|}{7,27143} & lor $(F)$ & $8,16 \mathrm{e}-23$ \\
\hline Log da verossimilhança & \multicolumn{2}{|c|}{$-439,4086$} & de Akaike & 972,8172 \\
\hline Critério de Schwarz & \multicolumn{2}{|c|}{1133,996} & annan-Quinn & 1037,848 \\
\hline rô & \multicolumn{2}{|c|}{0,02782} & -Watson & 1,63745 \\
\hline
\end{tabular}

Nota.*** Significante ao nível de $1 \%$;* Significante ao nível de 5\%; * Significante ao nível de $10 \%$.

Fonte: elaborada pelos autores.

Apesar do teste de Hausman mostrar que a abordagem de efeitos fixos se ajusta melhor ao modelo proposto, foi utilizado também o modelo de efeitos aleatórios, conforme Tabela 8. Mais uma vez, a variável MATA obteve o mesmo resultado da abordagem de efeitos fixos, o que evidencia que tal variável se relaciona de forma inversa com a maturidade das dívidas. Dessa forma, no ambiente brasileiro, infere-se que o prazo das dívidas não está alinhado com a maturidade dos ativos, como propõe a teoria. As razões podem estar nas imperfeições do mercado brasileiro, em decorrência da assimetria de informações entre os agentes ou até mesmo por conta dos aspectos institucionais (legais e econômicos) do país. Por fim, os resultados evidenciam uma relação direta e significante da variável RATA, contrariando os pressupostos teóricos e uma relação negativa e significante da variável ALAV, de igual modo refutando a teoria. 
Tabela 8

Resultados Dados em Painel com Efeitos-Aleatórios (GLS)

\begin{tabular}{c|c|c|c|c}
\hline & Coeficiente & Erro Padrão & razão-t & p-valor \\
\hline const & 9,9210 & 3,1873 & 3,1131 & $0,0021^{* * *}$ \\
OPOCR & $-0,1934$ & 0,1603 & $-1,2060$ & 0,0090 \\
LNROL & $-0,1847$ & 0,2092 & $-0,8826$ & 0,3784 \\
QUAL & $-0,1520$ & 0,2800 & $-0,5429$ & 0,878 \\
RATA & 0,8631 & 0,4810 & 1,7940 & $0,0741^{*}$ \\
RATB & 0,0793 & 0,8818 & 0,0899 & 0,9284 \\
TAXE & $-0,3446$ & 0,3180 & $-1,0842$ & 0,2797 \\
MATA & $-0,1497$ & 0,0522 & $-2,8671$ & $0,0045^{* * *}$ \\
ALAV & $-1,8628$ & 0,8598 & $-2,1670$ & $0,0314^{* *}$ \\
VAR & $-1,0441$ & 2,9010 & $-0,3599$ & 0,7193 \\
\hline Média var. dependente & 5,54206 & & D.P. var. dependente & 2,81172 \\
Soma resíd. quadrados & 1712,159 & & E.P. da regressão & 2,79608 \\
Log da verossimilhança & $-553,3607$ & & Critério de Akaike & 1126,721 \\
Critério de Schwarz & 1161,015 & & Critério Hannan-Quinn & 1140,558 \\
\hline Teste de Breusch-Pagan & Qui-quadrado $=90,7229$ & p-valor $=1,6527 \mathrm{e}-021$ \\
Teste de Hausman & Qui-quadrado $=28,9004$ & p-valor $=0,00067359$ \\
\hline
\end{tabular}

Nota.*** Significante ao nível de 1\%; ** Significante ao nível de 5\%; * Significante ao nível de $10 \%$.

Fonte: elaborado pelos autores.

Comparando-se os dois modelos de regressão linear (cross-section e dados em painel), nota-se melhor especificação e ajuste do modelo cross-section, bem como maior poder preditivo em relação ao modelo com dados em painel, de acordo com os resultados evidenciados nas Tabelas 6,7 e 8.

\section{Considerações Finais}

Uma decisão relevante na teoria de finanças corporativas refere-se à combinação entre dívidas e patrimônio líquido, com o objetivo de minimizar o custo de capital ou maximizar o valor da empresa. Entretanto, para que as empresas possam atingir sua estrutura ótima de capital, também é preciso analisar a maturidade adequada de suas dívidas. Para obter-se uma estrutura ótima de capital é necessário saber quanto e quando o fluxo de caixa futuro da empresa irá remunerar seus detentores de títulos.

O entendimento dos determinantes da maturidade das dívidas pode ser útil aos gestores, uma vez que, ao compreender quais são os fatores que a influenciam, esses possam antecipar suas decisões e melhor definir sua política de endividamento. Já para os bancos, ao compreenderem esses fatores, eles podem melhor ajustar as características de seus produtos às necessidades de seus clientes.

A fim de identificar quais determinantes tinham significância estatística, elaborou-se um modelo regressão linear múltipla - secção cruzada e dados em painel, com 8 variáveis independentes, para ser testado com base em amostra não aleatória, composta por 38 empresas não financeiras. Para a utilização desse tipo de modelo, suas premissas foram testadas e aprovadas. Como consequência, para 
a regressão cross section apenas a variável TAXE (Alíquota Efetiva de Tributos) apresentou resultado significativo e com o mesmo sinal apontado pela teoria. Com relação às demais variáveis, foi verificado que OPOCR, LNROL, MATA e ALAV possuem alto grau de correlação com a maturidade das dívidas. Todavia, o sinal apresentado foi o contrário, divergindo do proposto pela teoria.

Já para o modelo de dados em painel - efeitos fixos e aleatórios, as variáveis significativas foram MATA (Maturidade dos Ativos), ALAV (Alavancagem) e RATA (Rating Alto); porém seus coeficientes apresentaram sinal contrário ao proposto pela teoria.

Entre as limitações existentes, destaca-se a dificuldade de acesso ao rating das empresas por empresas especializadas, durante o período analisado (2002 a 2007). Por fim, recomenda-se que este estudo seja replicado, considerando outras variáveis independentes, tais como nível de governança corporativa, tangibilidade dos ativos, taxas de juros etc.

\section{Artigo recebido em 10.11.2009. Aprovado em 23.09.2010.}

\section{Referências}

Aivazian, V. A., Ge, Y., \& Qiu, J. (2005). Debt maturity structure and firm investment. Financial Management, 34(4), 107-119. doi: 10.1111/j.1755-053X.2005.tb00120.x

Barclay, M. J., \& Smith, C. W., Jr. (1995). The maturity structure of corporate debt. The Journal of Finance, 50(2), 609-631.

Berger, A. N., Espinosa-Vega, M. A., Frame, W. S., \& Miller, N. H. (2005). Debt maturity, risk, and asymmetric information. The Journal of Finance, 60(6), 2895-2923. doi:10.1111/j.15406261.2005.00820.x

Brick, I. E., \& Ravid, S. A. (1985). On the relevance of debt maturity structure. The Journal of Finance, 40(5), 1423-1437.

Diamond, D. (1991). Debt maturity and liquidity risk. Quarterly Journal of Economics, 106(3), 709737.

Flannery, M. (1986). Asymmetric information and risky debt maturity choice. The Journal of Finance, 4l(1), 19-37.

Goswami, G. (2000). Asset maturity, debt covenants, and debt maturity choice. Financial Review, 35(4), 51-68. doi: 10.1111/j.1540-6288.2000.tb01429.x

Gujarati, D. (2006). Econometria básica. Rio de Janeiro: Campus.

Hair, J. F., Black, W. C., Babin, B. J., Anderson, R. E., \& Tatham, R. L. (2009). Análise multivariada de dados (6a ed.). Porto Alegre: Bookman.

Highfield, M. J., Roskelley, K. D., \& Zhao, F. (2007). The determinants of the debt maturity decision for real estate investment trusts. The Journal of Real Estate Research, 29(2), 173-199.

Jiraporn, P., \& Kitsabunnarat, P. (2007). Debt maturity structure, shareholder rights, and corporate governance. Journal of Applied Finance, 17(2), 82-96.

Kale, J., \& Noe, T. H. (1990). Risky debt maturity choice in a sequencial game equilibrium. Journal of Finance Researches, 13(2), 155-165. 
Kane, A., Marcus, A. J., \& McDonald, R. L. (1985). Debt policy and the rate of return premium to leverage. Journal of Financial and Quantitative Analysis, 20(4), 479-499. doi: 10.2307/2330763

Lucas, D. J., \& McDonald, R. L. (1990). Equity issues and stock price dynamics. The Journal of Finance, 4(4), 1019-1043.

Myers, S. C. (1977). Determinants of corporate borrowing. Journal of Financial Economics, 5(2), 147-175. doi:10.1016/0304-405X(77)90015-0

Ozkan, A. (2000). An empirical analysis of corporate debt maturity structure. European Financial Management, 6(2), 197-212. doi: 10.1111/1468-036X.00120

Rochman, R. R., Eid, W., Jr., \& Laureano, G. L. (2009). Determinantes dos endividamentos de curto e longo prazos das empresas brasileiras. Anais do encontro Brasileiro de finanças, Canoas, RS, Brasil. Recuperado em 28 junho, 2010, de http://virtualbib.fgv.br/ocs/index.php/ebf/9EBF/paper/viewFile/872/155

Silva, A. F., \& Valle M. R. (2008). Análise da estrutura de endividamento: um estudo comparativo entre empresas brasileiras e americanas. Revista de Administração Contemporânea, 12(1), 201229. doi: 10.1590/S1415-65552008000100010

Smith, C. W. (1986). Investment banking and the capital acquisition process. Journal of Financial Economics, 15(1/2), 3-29. doi: 10.1016/0304-405X(86)90048-6

Smith, C. W., \& Warner, J. (1979). On financial contracting: an analysis of bond covenants. Journal of Financial Economics, 7(2), 117-161. doi: 10.1016/0304-405X(79)90011-4

Smith, C. W., \& Watts, R. (1992). The investment opportunity set and corporate financing, dividend, and compensation policies. Journal of Financial Economics, 32(3), 263-292. doi: 10.1016/0304-405X(92)90029-W

Stock, J. H., \& Watson, M. W. (2004). Econometria. São Paulo: Addison Wesley.

Stohs, M. H., \& Mauer, D. (1996). The determinants of corporate debt maturity structure. Journal of Business, 69(3), 279-312.

Titman, S., \& Wessels, R. (1988). The determinants of capital structure choice. The Journal of Finance, 43(1), 1-19.

Wooldridge, J. M. (2006). Introdução à econometria - uma abordagem moderna. São Paulo: Thomson Learning.

Yi, J. (2005). A study of debt maturity structure. The Journal of American Academy of Business, 7(2), 277-285. 